\title{
Bolhas urbanas: Estado, política habitacional e confinamento dos pobres
}

\section{Urban bubbles: State, housing policy and confinement of the poor}

\author{
Aldo Rezende \\ aldoenter@yahoo.com.br \\ Universidade Federal do Rio de Janeiro
}

\begin{abstract}
Resumo: Neste trabalho, busca-se, por intermédio de abordagens relacionadas à implementação do Programa de Arrendamento Residencial - PAR, destacar alguns aspectos relacionados à atuação do Estado na produção de espaços cuja configuração física e correspondente dinâmica social expressam e reafirmam territorialidades marcadas pela reprodução das desigualdades e contrastes socioespaciais. Contrapondo os discursos que afirmam ser a cidade para todos e para todas, tem-se, no confinamento dos pobres, a privatização de espaços públicos e flagrante conformação de um novo padrão de segregação socioespacial urbano.
\end{abstract}

Palavras-chave: Condomínio. Territorialidade. Segregação.

Abstract: In this work, through approaches related to the implementation of the Residential Leasing Program - PAR, we will seek to highlight some aspects related to State in the production of spaces whose physical configuration and corresponding social dynamics express and reaffirm territorialities reproduction of inequalities marked by contrast and socio-space. Contrasting discourses that claim the city is for everyone, the confinement effect of the poor holds the privatization of public spaces and evident formation of a new pattern of urban socio-spatial segregation.

Keywords: Condominium. Territoriality. Segregation.

Resumen: En este trabajo se buscará a través de enfoques relacionados con la aplicación del Programa de Arrendamiento Residencial - PAR, destacar algunos aspectos relacionados a la actuación del Estado en la producción de espacios, cuya configuración física y correspondiente dinámica social, expresan y reafirman territorialidades marcadas por la reproducción de las desigualdades y contrastes socio espaciales. Contraponiendo los discursos que afirman la ciudad para todos y para todas, tienen en el confinamiento de los pobres la privatización de espacios públicos y la flagrante conformación de un nuevo modelo de segregación socio espacial urbano.

Palabras Clave: Condominio. Territorialidad. Segregación. 


\section{INTRODUÇÃO}

$\mathrm{Na}$ atualidade, 84,35\% da população brasileira, aproximadamente 161 milhões de pessoas, vivem nas cidades (IBGE, 2010); não obstante, o fenômeno do crescimento das cidades brasileiras, em muitos casos, não acompanhado pelo processo de urbanização, resultou em grandes disparidades estruturais e consequentes desigualdades socioespaciais, principalmente em relação às formas e condições seletivas de acesso à terra.

Neste contexto, destacada a historicidade das dinâmicas questões urbanas e sociais resultantes das contradições do modelo de crescimento econômico implantado no país é que entendemos ser a crise urbano-habitacional, apenas uma das contradições estruturais presentes nas cidades e no cotidiano do modo de vida urbano em suas singularidades.

Os conflitos urbanos hoje evidenciados nas principais cidades brasileiras prenunciam e/ ou confirmam a falência do modelo de cidade funcional, historicamente estruturada na lógica do dinâmico processo de reprodução das relações sociais de produção do capital em suas respectivas fases de ascensão e respectivas contradições.

Do esgotamento do modelo de cidade fordista, outros arranjos socioeconômicos espaciais parecem dar mostras de um novo processo de cidade em formação, sendo, contudo, conformado na flagrante e intensa fragmentação, despolitização e ressignificação do espaço público, em muitos casos, através de políticas públicas intervencionistas ditas de interesse social.

De forma pontual, a reflexão ora proposta parte da tentativa de apreensão de um possível novo padrão socioespacial de reprodução de desigualdades com base na implantação de condomínios populares fechados no âmbito da política habitacional de interesse social do Governo Federal.

Uma vez consideradas as diversas abordagens e reflexões sobre a produção do espaço urbano em suas respectivas formas e conteúdos sociais, buscaremos, no âmbito geral da apreensão do tema, ressaltar diretrizes da política habitacional, especificamente relacionadas ao Programa de Arrendamento Residencial-PAR, instituído pelo Decreto 10188/2001, seguidamente alterado por outras iniciativas de legislação recorrente.

Por intermédio da análise parcial sobre um dos empreendimentos do PAR, localizado no município de Vila Velha - ES, destacaremos aspectos relacionados ao papel do estado corporativo na perspectiva da reprodução das desigualdades socioespaciais e conformação de microterritorialidades no âmbito do controle social e imposição do modo de vida nos condomínios populares.

\section{ESPAÇO URBANO: FORMA E CONTEÚDO SOCIAL}

\footnotetext{
“A brutalidade é a violência dos fracos. A violência dos poderosos é calma, fria, segura de si mesma; suas técnicas de opressão são discretas, refinadas e, enfim, terrivelmente eficazes" (LAPIERRE).
} 
Uma vez considerado em sua totalidade social, o espaço urbano da cidade capitalista expressa as singularidades do processo histórico da materialidade (sistema de engenharias) presente na estruturação e organização espacial com base em objetos e ações definidos em suas respectivas e dinâmicas formas, funções e conteúdos sociais.

Na perspectiva geográfica de leitura sobre a estrutura de organização espacial, novas práticas e dinâmicas sociais são definidas, redefinidas e engendradas pela e na configuração territorial do espaço urbano: fragmentado e simultaneamente articulado, reflexo e condicionante social para uns (CORREA, 1995, p.9); o espaço também é entendido na lógica da não determinação da forma sobre o conteúdo social, sendo mais do que simples reflexo da sociedade (GOMES, 2010, p.172).

Da materialidade das formas espaciais resultantes da atuação dos agentes sociais concretos, revela-se também o sentido da estrutura social no contexto dos processos de organização da sociedade, engendrados nas e pelas relações sociais de produção e consumo do espaço urbano cada vez mais hierarquizado, fragmentado e segregado, possibilitando reconhecer microterritorialidades que se estabelecem.

Uma vez reconhecidas as formas de apropriação, uso e ocupação do solo, pela configuração física e territorial, torna-se possível analisar e apreender as práticas e dinâmicas sociais que possibilitam revelar o conteúdo social do espaço ocupado, experienciado e vivenciado no cotidiano das relações consolidadas.

Nestes termos, nos processos de produção do espaço urbano, reconhecida a condição de reflexo e condicionante social, nota-se ser cada vez mais efetivo e dinâmico, o papel dos agentes produtores e consumidores em estratégias de acumulação por vezes materializadas a partir da configuração territorial e respectivas territorialidades - expressão peculiar da dinâmica social correspondente.

Além dos proprietários dos meios de produção, dos proprietários fundiários e dos promotores imobiliários, é reconhecida a preponderante e histórica presença do Estado: agente ativo no dinâmico processo de organização espacial da cidade em suas contradições estruturais.

Na condição de reflexo da atuação dos agentes produtores e consumidores do espaço urbano e através dos arranjos institucionais para elaboração e implementação de programas e projetos habitacionais rotulados como de interesse social, é que nota-se exacerbado o fenômeno de fragmentação, hierarquização e seletividade socioespacial nas principais cidades-metrópoles brasileiras. Desta forma, tem-se produzido territórios descontínuos e desintegrados que suscitam reconhecer um embrionário padrão de seletividade socioespacial, marcadamente expresso em formas urbanas de enclaves fortificados para os ricos e de confinamento para os pobres na reprodução mimética do "estilo burguês" de morar.

Trata-se de formas urbanas, denominadas condomínios populares fechados, que expõem a lógica da acumulação capitalista através dos padrões de racionalidade no processo de produção de habitações de interesse social. Assim, sobrepondo-se à pretendida qualidade de vida do habitat, prevalecem a quantidade e a economia de 
escala no processo construtivo de unidades habitacionais em espaços compactos, além da configuração de territórios inóspitos de vida e moradia para pobres.

\subsection{Espaço Urbano: territórios e territorialidades}

O território é o lugar em que se desembocam todas as ações, todas as paixões, todos os poderes, todas as forças, todas as fraquezas, isto é, onde a história do homem plenamente se realiza a partir das manifestações da sua existência. (SANTOS, 1999, p.2).

Para os pobres, cada vez mais, a cidade enquanto desejável território de realizações e do desejo por dias melhores, paulatinamente sucumbe aos sinais de negação, seletividade socioespacial, precarização social e erosão de direitos.

$\mathrm{Na}$ cidade-mercadoria, diante das barreiras visíveis e invisíveis que definem territorialidades distintas que se negam e se complementam, a predominância da ideologia do individual sobre o coletivo e do privado sobre o público fragmenta, isola e enfraquece os laços sociais, reafirmando as distâncias físicas e sociais.

Neste contexto, a despolitização baliza as iniciativas de regulação e controle social também por intermédio de formas urbanas e mecanismos de controle biopolítico das massas, propalado pelos discursos e efetivados por práticas políticas de planejamento e gestão do território. Assim, uma vez desvelada, a realidade se impõe contraditória; a cidade é ressignificada também pelos espaços e objetos monumentais que negam a presença do "ser"; nos espaços públicos de controle privado; nos territórios regulados por barreiras visíveis e invisíveis que expressam sentidos e significados de microterritorialidades dinâmicas e distintas (REZENDE, 2007, p.3).

Da condição de pobre, subalterno à possibilidade de pretenso ator e cidadão, idealizado e reverenciado na retórica dos discursos e nas diretrizes das atuais políticas sociais, a propalada cidadania acaba reduzida a iniciativas neoliberais de inclusão do pobre à condição de mero agente consumidor e cliente, cidadão sem vez e sem voz no território das políticas e das práticas do consenso.

Nestes termos, nos atuais e emblemáticos espaços de disputas - cenários da "guerra de poder", as formas de representações construídas na perspectiva de enfrentamento ao projeto neoliberal são em muitos casos contraditórias, além de revelar a "confluência perversa de projetos políticos antagônicos em disputa" (DAGNINO, 2002, p. 2).

Notadamente, diante do atual modelo de "empresariamento" das cidades, são cada vez mais presentes e marcantes os mecanismos de negação e de repressão ao insurgente papel do ator ativo no movimento histórico de luta pelo direito de ter direitos. A gramática do consenso tornou-se dispositivo de manipulação, descaracterização e dissolução dos conflitos sociais então remediados.

Neste contexto de evidentes contradições, é da assustadora velocidade e intensidade do processo de crescimento urbano que novas territorialidades são definidas e redefinidas, conformadas pelos e nos princípios da ideologia neoliberal de produção e consumo do espaço urbano na lógica da acumulação capitalista. 
Da configuração territorial apreendida a partir da morfologia circunscrita à dinâmica dos processos de organização e de definição do conteúdo socioespacial, o "território usado" (SANTOS, 1999, p.1) estruturado mostra-se multifacetado em suas distintivas territorialidades e microterritorialidades no plano objetivo e subjetivo, relacionado principalmente ao cotidiano do modo de vida e na expressão de nuances da identidade do lugar.

De acordo com Santos (1999, p.2):

O território não é apenas o conjunto dos sistemas naturais e de sistemas de coisas superpostas. O território tem que ser entendido como um território usado, não o território em si. O território usado é o chão mais a identidade. A identidade é o sentimento de pertencer àquilo que nos pertence. O território é o fundamento do trabalho, o lugar da residência, das trocas materiais e espirituais e do exercício da vida.

Na cidade enquanto território usado, os subalternos são espoliados pelas e nas relações de dominação e de poder dos agentes de produção, reprodução e consumo do espaço urbano, tendo em vista principalmente a perspectiva de interesses do mercado e à custa do agravamento das questões sociais urbanas e negação do exercício pleno da cidadania.

Assim, no campo da disputa de projetos antagônicos, a negação do direito à cidade se efetiva também por intermédio de programas habitacionais que ditos de interesse social, impõe formas de uso e ocupação do solo assim como, de controle biopolítico e social pela imposição de modos de vida, reafirmando contradições e reproduzindo desigualdades.

É através da afirmação de "outras" territorialidades impostas de "fora para dentro", que os condomínios populares fechados produzidos pelo Estado corporativo, passaram a expressar uma embrionária forma urbana de flagrante e declarada privatização do espaço público pela tentativa de confinamento dos pobres e de expressão de microterritorialidades de grupos que se anulam.

\section{PROGRAMA DE ARRENDAMENTO RESIDENCIAL - PAR: RECLUSÃO TERRITORIAL E REPRODUÇÃO DAS DESIGUALDADES SOCIOESPACIAIS}

Uma vez reestruturado, o Programa de Arrendamento Residencial passou a ser implementado com recursos oriundos de fundos diversos, principalmente na contratação de operações de crédito junto ao Fundo de Garantia por Tempo de Serviço - FGTS.

De acordo com prerrogativas da Lei 10.188/2001, a Caixa Econômica Federal tornou-se o agente operador e gestor do PAR sendo, portanto, constituído o Fundo de Arrendamento Residencial - FAR.

Na função de agente operador e gestor, a Caixa Econômica Federal passou a ser remunerada com valores fixados pela Secretaria Especial de Desenvolvimento Urbano da Presidência da República, também responsável pelo acompanhamento e avaliação de desempenho do PAR. 
Atuando inicialmente na aquisição de patrimônio imobiliário e, por conseguinte, na gestão dos imóveis arrendados inicialmente na captação de Arrendamento a Caixa Econômica o de Investimento Social-FINSOCIAL, criado em 1982, para fins exclusivos de moradia destinada aos trabalhadores de baixa renda, a Caixa Econômica Federal passou a atuar com exclusividade também na gestão de todo o processo de arrendamento com opção de compra pelo arrendatário.

Conforme estabelecido pela Portaria 301 de 2006, no Programa de Arrendamento Residencial, enquanto política considerada de interesse social, dentre as principais diretrizes, ressalta-se a "promoção da melhoria da qualidade de vida das famílias beneficiadas".

No âmbito das diretrizes estruturantes do Programa de Arrendamento Residencial, conformaram-se as estratégias de alcance político e social voltadas para a legitimação política a partir de um amplo leque de alianças que possibilitou o desenho da hegemonia necessária à condução da política habitacional do novo governo.

Nestes termos, buscando a superação dos reflexos da crise capitalista internacional, o aquecimento da economia interna foi possível também a partir da política de subsídios e incentivos à cadeia produtiva da construção civil no contexto da política habitacional do governo. Assim, uma vez assegurado a geração de empregos para o expressivo contingente de trabalhadores assalariados, o incremento das contas do FGTS possibilitou retroalimentar a dinâmica de financiamento da política habitacional conforme interesses dos agentes envolvidos.

Desta forma, além da cadeia produtiva da construção civil, os setores imobiliários e do mercado de terras, os bancos comerciais e as grandes construtoras passaram a influenciar os processos de controle e comando das estratégias de implementação das políticas urbano-habitacionais.

Para além da garantia da infraestrutura e de equipamentos urbanos, o Estado tornou-se importante agente no processo de produção e consumo do espaço urbano com farta disponibilização de recursos por meio de subsídios e financiamentos a programas e projetos urbano-habitacionais.

Neste contexto, novamente reafirma-se a preocupação com a reposição de estoque de moradia, oportunidade em que o aspecto quantitativo sobrepõe ao qualitativo através da produção em série de moradias padronizadas, em menor número, destinadas as classes subalternas, predominantemente com renda comprovada de até três salários.

Com operações orquestradas entre mercado de terras, construtoras, bancos e poder público corporativo, os projetos passaram a ser definidos prioritariamente na lógica da otimização de resultados e efetiva viabilidade financeira na perspectiva de garantia da acumulação em todas as fases, conforme interesses dos agentes envolvidos.

No nível macroeconômico, medidas compensadoras foram promovidas pelo Governo Federal a exemplo da redução da carga tributária em benefício de todos os agentes envolvidos: incorporação e produção de unidades habitacionais para fins de arrendamento. 
No âmbito do Poder Público Municipal, a isenção e redução de impostos, o afrouxamento da lei de parcelamento do solo, da legislação urbanística e edilícia além da flexibilização dos planos diretores municipais, possibilitaram assegurar a otimização do processo construtivo e a garantia da lucratividade na produção de moradias na forma de condomínios populares fechados com o do Programa de Arrendamento Residencial.

O quadro de vantagens corporativas estruturado possibilitou a produção de plantas compactas no estilo de condomínios verticais e horizontais, com reduzido custo nas correspondentes fases de concepção e execução dos projetos, tendo em vista as estratégias de relaxamento da legislação, além da capitalização com a renda da terra, a localização e otimização quanto ao volume construtivo e o aproveitamento do espaço edificado.

As unidades habitacionais passaram a ser produzidas em série, variando de $30 \mathrm{a}$ 43 metros quadrados, com precário acabamento, numa paisagem monótona. Na maioria das vezes, tratam-se de condomínios populares fechados construídos em bairros da periferia, reiterando a expressão do fenômeno da segregação socioespacial no contraponto das prerrogativas relacionadas à função social da terra urbana contidas no Estatuto da Cidade, Lei Federal 10257/2001.

Contrariando os pressupostos da legislação urbanística vigente, a forma urbana denominada condomínio popular fechado permite perceber além a "lógica do arranjo corporativo" presente no paradoxo estabelecido entre o discurso e a prática do e no pensar e planejar a cidade. Com exclusividade, a Caixa Econômica Federal - CEF, através das Regionais de Sustentação ao Negócio Alienar Bens Móveis e Imóveis, na prerrogativa de agente gestor da política habitacional, exerce o controle do modo de vida dos trabalhadores, confinados nos condomínios populares.

O controle social é exercido por um único modelo de Termo de Convenção e do Regimento Interno, que são padronizados e impostos indistintamente aos moradores empreendimentos do PAR em todo o país. Neste contexto, a Caixa Econômica Federal promoveu a emergência de um novo agente: as empresas administradoras, contratadas na condição de co-gestores dos empreendimentos arrendados aos trabalhadores de baixa renda.

Também na elaboração e imposição da planilha de previsão de gastos anuais do condomínio, a Caixa Econômica Federal e as empresa administradoras passaram a definir os critérios de cobrança das taxas de manutenção, classificadas em ordinárias e extraordinárias, oportunidade em que a espoliação dos arrendatários se efetiva com a vinculação do percentual de ganho mensal das empresas administradoras à receita mensal dos condomínios. Além das taxas mensais de arrendamento e condomínio, sob a responsabilidade dos arrendatários, incidem as tarifas de água, luz, gás, Imposto Predial e Territorial Urbano - IPTU, dentre outras taxas e tributos.

Na perspectiva de atuação corporativa entre os agentes partícipes do processo de gestão do PAR, a empresa administradora, no ato do contrato assinado com a CEF, percebe $9,5 \%$ sobre o valor total dos contratos de arrendamento, podendo ser aditivado anualmente, assim como $10 \%$ da receita mensal do condomínio, a título de taxa de administração, pago pelos arrendatários. 
Por sua vez, a empresa administradora controla a conta bancária e quarteiriza os serviços de portaria e de limpeza, também pagos pelos arrendatários. Através do contrato de arrendamento vinculado ao termo de convenção e regimento interno impostos aos arrendatários, a racionalidade burocrática do banco se faz prevalecer num visível panorama de constrangimento e coerção, em muitos casos de vigilância disciplinar quanto ao modo de vida dos arrendatários.

Contrapondo as diretrizes urbanísticas do Estatuto das Cidades, a implantação de condomínios populares fechados, em muitos casos, reforçou o quadro de segregação socioespacial na medida em que também permitiu conformar a reprodução mimética dos enclaves fortificados, permeados pelo discurso da distinção e da "segurança garantida."

Assiste-se, assim, ao recuo do Estado de suas funções essenciais de garantia do direito à segurança pública, neste caso, em especial, negada aos arrendatários por se tratar de uma forma urbana tipificada na condição de espaço privado, onde o serviço preventivo de segurança pública não existe. Em muitos casos, considerada a localização dos referidos condomínios populares fechados, além da falta de segurança, também a ausência de equipamentos comunitários se faz notar a exemplo de escolas, creches e unidades de saúde, assim como de serviços de transporte público de qualidade.

\title{
4 CONDOMÍNIO POPULAR FECHADO: FORMA E CONTEÚDO SOCIAL
}

\begin{abstract}
No começo eu me sentia importante e achava chique quando falava para meus amigos que estava morando em um condomínio fechado. Agora, passou quatro anos, a ficha caiu. Eu estou é num campo de concentração, trancafiado num caixote; eu, minha mulher e filhos, cercados por um muro de 3 metros de altura e sendo mandado pela Caixa Econômica Federal que dita as normas aqui. Eles trata a gente como se fosse mercadoria descartável. Hoje eu sei que este muro só serve para separar pobres de dentro dos pobres de fora que acham que nós de dentro somos ricos. Disseram que o muro e o portão são para garantir a segurança. Outro dia destes morreu o filho de um vizinho. Os traficantes entraram no condomínio, começaram a balear o rapaz dentro de casa e acabaram de matar o pobre no meio da rua. Ai a ficha caiu mais ainda... cadê a segurança prometida? ${ }^{1}$
\end{abstract}

Nos espaços produzidos, denominados condomínios populares fechados, o sentido da materialidade revela o "fechamento dos pobres em espaços extremamente precarizados de sobrevivência cotidiana" (HAESBAERT, 2004, p.16), desvelando a expressão de microterritorialidades na formação de grupos de arrendatários que se autosegregam, tanto pelo simbolismo da "distinção" do status de morar, quanto pela omissão e medo às represálias dos agentes gestor e administrador.

Em muitos dos casos, a condição de desemprego ou mesmo de comprometimento da renda familiar leva arrendatários à condição de inadimplência, estabelecendo assim a

1 Entrevista de, concedida ao autor por uma liderança do Movimento Jacarenema de Luta pelo Direito de Morar com Dignidade, no Residencial Jacarenema, em Vila Velha - ES (21/10/2010). 
condição de moeda de troca- arrendatários e agentes gestores, quando passa a perpetuar o silêncio, o medo e a recusa de grupos de arrendatários em participar das iniciativas de luta pelo direito de ter direitos no lugar.

A microterritorizalização destes grupos de arrendatários se efetiva em códigos de convivência, regras sociais e interesses discursivos que confirmam um determinado modo de vida, por sua vez, reflexo e condicionante de um espaço socioterritorial fragmentado em permanente conflito de interesses e disputas.

No campo da afirmação das contradições e conflitos, o Termo de Convenção padronizado não prevê a forma de gestão possível num campo de diversidades e controvérsias que pode envolver desde arrendatários a proprietário, financiadores e inquilinos todos convivendo num mesmo espaço de moradia segregado.

Diante da estratégia de fragmentação, segregação socioespacial estabelecida e dos mecanismos de controle social impostos pelos agentes gestor e administrador dos condomínios populares fechados do PAR, nota-se que na perspectiva das microterritorialidades estabelecidas, o conceito de cidadania é diluído na flagrante impossibilidade de construção e afirmação da identidade do lugar em sua totalidade social.

\section{CONSIDERAÇÕES FINAIS}

Nos programas habitacionais considerados de interesse social, predominantemente o caráter quantitativo sobrepõe-se ao critério da qualidade, quando centenas e milhares de unidades habitacionais padronizadas são construídas em áreas centrais degradadas e mais expressivamente nas periferias das principais cidades - em locais desprovidos do mínimo necessário a condições de habitabilidade.

Principalmente por causa da movimentação do setor industrial, em especial, da cadeia produtiva da construção civil e do mercado de terras, as desigualdades socioespaciais são historicamente produzidas e reproduzidas. Isto se dá na proporção em que o direito à cidade e à moradia são, cada vez mais seletivos e, portanto, excludentes, dadas as condições de acesso restrito, balizado pela faixa de renda salarial, pelo excesso de burocracia e exigências dos agentes privados na gestão das políticas públicas.

Para além da apreensão sobre a questão habitacional no viés do déficit habitacional quantitativo e qualitativo, a alarmante falta de moradia, uma vez concentrada nas classes subalternas, com renda de até três salários mínimos, é, por sua vez, silenciada pelos parcos subsídios governamentais; subsídios incompatíveis com os interesses de acumulação praticada pelos agentes produtores e consumidores do espaço.

A partir dos resultados das eleições presidenciais de 2002, nem mesmo a expressão simbólica engendrada na nova conjuntura política marcada pela ascensão das consideradas "forças progressistas" conseguiu camuflar os visíveis paradoxos que desafiam o conteúdo político do discurso historicamente fundado na retórica do direito à moradia com dignidade e à cidade para todos. 
$\mathrm{Na}$ esteira dos arranjos de interesses de classes ocorridos quando da elaboração e execução da política nacional de habitação através do BNH (1968-1986), na atualidade, também as estratégias de dinamização da economia via arranjos institucionais e de interesses de classes continuam determinando a elaboração e execução das políticas urbano-habitacionais de acordo com a lógica de interesses do mercado.

A atuação da Caixa Econômica Federal na qualidade de agente operacional e gestor de programas urbano-habitacionais de interesse social afirma o caráter de privatização da política habitacional e de intervenção urbana, sendo que a predominância dos interesses econômicos sobrepõe-se aos sociais, visíveis também no acirramento dos processos de fragmentação e segregação socioespacial nas cidades.

$\mathrm{Na}$ faixa de renda compreendida em até três salários mínimos, a expressiva demanda de brasileiros sem-teto continua alijada do direito à moradia e estacionada fora da "curva de interesses do mercado", por sua vez comandado pelas forças hegemônicas de controle da política habitacional: principalmente as grandes empresas construtoras, bancos e pelo mercado de terras.

A construção de condomínio popular fechado, localizados principalmente em bairros pobres já estabelecidos na periferia das grandes cidades, permite reconhecer o embrionário surgimento de "bolhas urbanas", figurativamente assim designado haja vista a reconhecida forma urbana de confinamento de pobres que promete implodir em suas contradições historicamente acumuladas.

Os condomínios populares fechados passaram a reproduzir a forma mimética do estilo de moradia das classes abastadas, corroborando a contemplação dos interesses de otimização de resultados e garantia da lucratividade, também efetivados no maior coeficiente de aproveitamento do espaço edificado, na produção de unidades habitacionais geminada, padronizadas, em maior quantidade e no inferior padrão de acabamento.

Se de um lado a construção de condomínios populares verticais e horizontais fechados, corresponde à lógica da compacta e expressa forma de uso e ocupação do espaço urbano, de outro, resulta em evidentes sinais de reprodução das desigualdades, principalmente se considerada a contraditória sobreposição do aspecto quantitativo sobre o pressuposto da qualidade de vida propalado enquanto uma das principais diretrizes do PAR.

Na condição de "bolhas urbanas" e longe de garantir a segurança prometida sob o "guarda-chuva" do Estado corporativo, grandes e reconhecidas empresas construtoras passaram, em quantidades insignificantes diante do volume de recursos disponibilizados, a produzir condomínios populares, tendo em vista, principalmente as facilidades resultantes dos arranjos para a garantida reprodução e acumulação de capital.

Se no passado recente, a centralidade das políticas de nível federal, as práticas clientelistas dos governantes municipais, a ausência de legislação fundiária, urbanística e edilícia assim como a carência de técnicos qualificados foram considerados entraves ao ideário da reforma urbana pretendida, na atualidade, superados alguns destes entraves, novos paradoxos se estabelecem.

A implantação de condomínios populares horizontais fechados, edificados em áreas segregadas, permitem reconhecer a notória anomalia na dupla segregação 
socioespacial que uma vez institucionalizada, ao impactar a realidade local, nega também os pressupostos do ideário da reforma urbana contido no Estatuto da Cidade, acirrando ainda o processo de fragmentação e revelando microterritorialidades a partir de grupos sociais adversos.

No contexto das microterritorialidades estabelecidas principalmente a partir da arbitrária forma de imposição de um novo modo de vida, nota-se efetivar o comprometimento das possibilidades inspiradas em preceitos democráticos de construção da identidade do lugar, do sentido de pertencimento e da possibilidade da prática efetiva de exercício da cidadania: condições necessárias para assegurar a coesão social e o sentido da vida em comunidade.

No presente contexto, uma vez negada a fruição, o exercício pleno da civilidade à custa dos interesses dos agentes capitalistas de produção e consumo do espaço urbano, ancorados na "benevolente" ação do Estado corporativo, novas territorialidades e microterritorialidades se afirmam e contraditoriamente se negam.

Na evidência de microterritorialidades definidas pelo processo de fomento a fragmentação, a segregação e a reclusão territorial, o confinamento dos pobres possibilita apreender situações limites de frágil coesão social capaz de levar ao mais alto nível de "intolerância".

No caso específico do PAR, a imposição do Termo de Convenção e do Regimento Interno padronizado em nível nacional torna flagrante o comprometimento do modo de vida dos trabalhadores, principalmente se consideradas as diversidades quanto às situações de moradia a serem deflagradas. Além da condição de arrendatários já prevista e normatizada, a condição de proprietários, financiadores, inquilinos, além de outros modos simultâneos de ocupação das unidades habitacionais não foram levadas em consideração pelos citados documentos reguladores do modo de vida dos trabalhadores.

Confinar pobres em unidades habitacionais com dimensões reduzidas, sem conforto e privacidade, submetidos à política coercitiva de gestão do espaço de vida-negócio, são algumas das condições que expõem microterritorialidades marcadas pelo acelerado processo de despolitização, afirmação do individual sobre o coletivo e precarização das relações sociais.

Neste declarado contexto de atuação do Estado corporativo na reprodução das desigualdades, a "reclusão socioterritorial homogeneizada" vai se tornando regra na lógica da naturalização da forma privada de demarcação de territórios, cujas microterritorialidades parecem apontar para a total precarização socioespacial das e nas cidades brasileiras.

\section{REFERÊNCIAS}

CORREA, Roberto Lobato. O espaço urbano. 3. ed. São Paulo: Ed. Ática, 1995.

DAGNINO, Evelina. ¿Sociedade civil, participação e cidadania: de que estamos falando? En: Daniel Mato (Coord.). Políticas de ciudadanía y sociedad civil en tiempos de globalización. Caracas: FACES/ Universidad Central de Venezuela, 2004. p. 95-110. 
FRUGOLI Jr., Heitor. Sociabilidade urbana. Rio e Janeiro: Jorge Zahar Editores, 2007.

GOMES, Paulo César da Costa. A condição urbana: ensaios da geopolítica da cidade. 2. ed. Rio de janeiro: Bertrand do Brasil, 2006.

IBGE. Censo demográfico. Rio de Janeiro: 2010.

REZENDE, Aldo. Bolhas urbanas: na contramão do direito a cidade, o paradoxo da segregação sócioespacial institucionalizada. Universidade do Chile. Departamento de Arquitetura e Urbanismo. Santiago, Chile, Novembro/2007.

SANTOS, Milton. A urbanização brasileira. 5. ed. São Paulo: Edusp, 2005.

. O dinheiro e o território. GEOgraphia, ano 1, n.1, 1999. Disponível em: <http://www.uff.br/ geographia/ojs/index.php/geographia/article/view/2/2 >. Acesso em: dezembro de 2011.

Recebido em 23/01/2012

Aceito para publicação em 08/04/2012 